\title{
Investigations on the influence of heat on AA1050 sheet during incremental forming
}

\author{
S. A. Singh, S. Priyadarshi, P. Tandon ${ }^{\dagger}$ \\ †ptandon@iiitdmj.ac.in \\ deLOGIC Lab, Mechanical Engineering Discipline, PDPM Indian Institute of Information Technology Design and \\ Manufacturing, M. P., Jabalpur, 482005 India
}

With the advancement in technologies, Incremental Forming (IF) emerges as one of the best solutions for exclusive forming of components. As the demand of industrial products shifts from mass production to mass customization, IF process gives an option to produce components having unique features. The overall cost, when compared with other conventional forming techniques, is low, and the process is highly flexible and efficient. However, the behaviour of materials plays a vital role in the effectiveness of the process. The material properties, being highly dependent on temperature, influence the process outcomes. Various differential trends in the results are observed when the IF is carried out in different thermal conditions. The work presents a comprehensive study of the IF process on an Aluminium Alloy (AA1050) sheet at different heating conditions. The IF was initially carried out on a commercially available AA1050 sheet blank at average room temperature. Afterward, the process was done by heating the sheet during the IF operation. Besides, the IF process on the preheated sheet was studied from the literature. The observations for IF process in different forming conditions are distinct. The results were highly influenced by heat and thermal conditions. With the help of numerical simulations and experimental investigations, the differences in the outcomes are quantified. The results in terms of strain energy, stresses induced, springback in formed components along with minimum thickness and surface quality, recommend the use of heat in controlled amount during the incremental forming process.

Keywords: incremental forming, aluminium alloy AA1050, temperature.

\section{Introduction}

With rapid changes in market demand, technology has to evolve at the same pace. Product demand is of late shifting from mass production to mass customization. Incremental forming is one of such technologies, which is catering the mass customization of products. For manufacturing of different types of objects, with variations in geometry and specifications, IF offers one of the best and reliable solutions. As IF process is a dieless manufacturing process, it does not require shape specific tools and dies [1]. A cylindrical tool mounted on a Computer Numeric Control (CNC) machine can produce any possible formed shapes. The blank to be formed is clamped at its outer edges through clamps and fixtures as shown in Fig. 1. The toolpath is developed according to the shape required, and thus, the only variant in an IF operation.

The effectiveness of the IF process depends upon its specific parameters. The parameters like blank sheet material, tool material, sheet thickness, and tool diameter have a significant impact on the IF process. It has been recommended that the hardness of tool material must be at least $40 \%$ more than that of the sheet to be formed [2]. Besides, the radius of the tool used in IF process must be at least three times the sheet thickness for efficient forming of the components [3].

The outcome of the IF process highly depends on the material used as a sheet blank. For any forming operation, the formability of the material is essential. The formability of the material depends on the amount of elongation that occurs in the tensile test before any breakage. The intermolecular structures are responsible for the elongation and indirectly influence the formability of the material [4]. The efficiency of a forming process increases with increase in formability of the blank material. IF process provides decent results with good to form materials; however, geometrical inaccuracy due to the springback is one of the significant problems of the process [5]. Besides, surface quality obtained by the IF process is poor in comparison to the conventional forming operation. Various researches have been conducted to eliminate these problems from the prevailing IF process.

The formability of material can be enhanced by forming at elevated temperatures [6], as due to heat, yield strength of material reduces, which enhances its formability [7]. Although hot forming improves the formability, it also causes severe changes in the metallurgical properties of the material. The present work attempts to cover the IF process at three different forming conditions and discuss their traits. Efforts were undertaken to understand the influence of temperature on incremental forming of AA1050 sheet on various process characteristics. Numerical simulations along with experiments were conducted to observe the results. It was concluded that heating the sheet can be a solution to improve the efficiency of incremental forming, but it must be done in a controlled amount and by an appropriate method. 


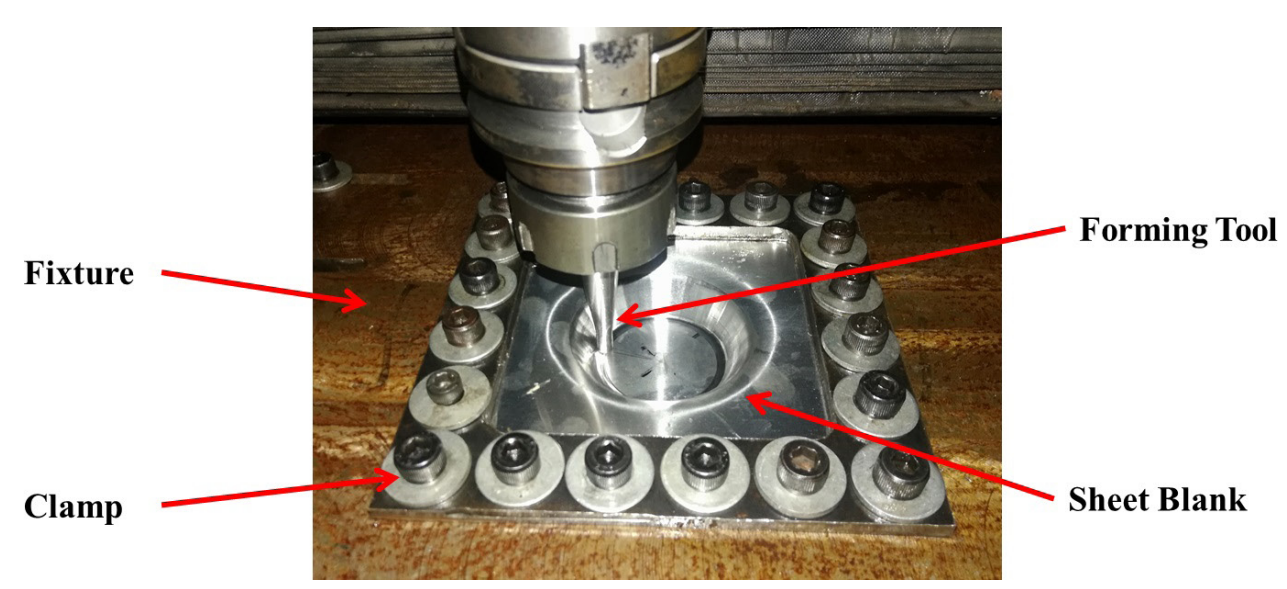

Fig. 1. (Color online) Incremental forming setup.

\section{Materials and methodology}

The incremental forming process begins with Computer Aided Design (CAD) of the required shape, from where the toolpath is deduced. Here, the CAD model was prepared on CATIA VR15 software. The toolpath is the contour of the outermost surface of the solid model, on which tool traverses. The CAD model and its toolpath for a conical geometry are shown in Fig. 2.

The present work was initiated to eliminate the limitations of the IF process with the use of external heat. The research work is focused on the commercially available aluminium alloy AA1050 sheet. The blank having a thickness of $1 \mathrm{~mm}$ is utilized during the experimentations. The material properties of the AA1050 were initially obtained from tensile tests carried out on AA1050 at different temperatures. The task was done with the help of physical simulation system GLEEBLE 3500. The selection of temperature for performing the IF process was a challenging task. It was recommended to perform warm forming at a temperature lower than the recrystallization temperature of the material. The recrystallization temperature of the materials lies in the range of $0.25 T_{m}$ to $0.45 T_{m}$, where $T_{m}$ is the melting point. The melting point temperature of AA1050 is approximately $650^{\circ} \mathrm{C}$, so the range of temperature available for warm forming is $150^{\circ} \mathrm{C}$ to $300^{\circ} \mathrm{C}$. A stainless-steel tool with $8 \mathrm{~mm}$ diameter and a hemispherical tip was utilized as a forming tool. It must be noted that no lubrication was applied in the interface of tool and sheet blank during the experimental investigations. The setup shown in Fig. 3 is used for the experimentations.

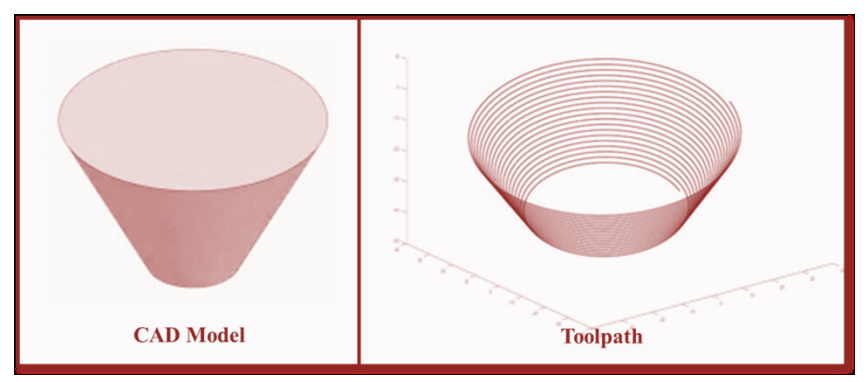

Fig. 2. CAD model and toolpath.

\section{Investigations}

The investigation started with a thorough study of the work done by Shrivastava et al. [8,9]. Preheating phenomena was employed by them to enhance the process capabilities of the IF process. The effect of preheating on global springback in incrementally formed AA1050 sheets was analyzed. Due to preheating, grain structure reforms and consequently formability improves. However, it was clearly stated that preheating done at higher temperatures like $330^{\circ} \mathrm{C}$ and $500^{\circ} \mathrm{C}$ deteriorated the surface quality due to the homogenization of grain orientation, which led to the orange peel effect.

As the temperature plays a vital role in the behaviour of the process, the selection of a proper temperature range is essential. From the tensile tests, it was evident that with an increase in temperature, the elongation increases, while the yield stress decreases. These two factors are responsible for the enhancement in the formability of the material. However, for the exact estimation, numerical simulation and experimental investigations were performed.

A finite element analysis (FEA) model was prepared and processed in Abaqus/CAE package. A truncated cone having a wall angle of $65^{\circ}$ with an upper diameter of $70 \mathrm{~mm}$ was

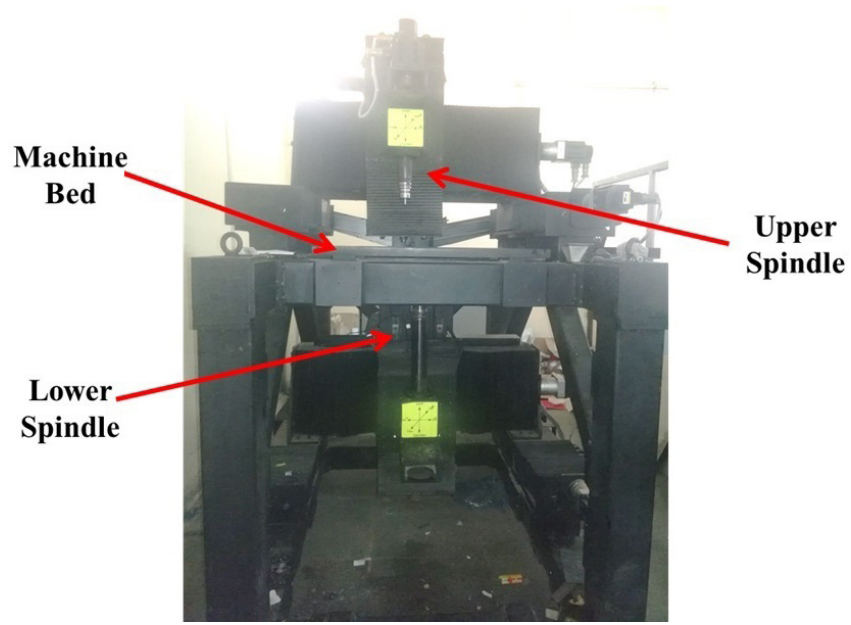

Fig. 3. (Color online) Experimental setup for incremental sheet metal forming. 
selected as the test geometry. With the tool of $8 \mathrm{~mm}$ diameter, the blank sheet of dimension $100 \mathrm{~mm} \times 100 \mathrm{~mm} \times 1 \mathrm{~mm}$ was considered, as shown in Fig. 4. The surface to surface contact condition and 0.1 penalty value (to compensate the friction) was imposed at the interface of tooltip and sheet blank surface. The outer edges of the sheet blank were restricted by zero degrees of freedom and the toolpath in terms of smooth step was allocated to the reference point taken at the tooltip. The material properties of AA1050 were assigned to the sheet blank, and the tool was assumed to be rigid; hence, no material properties were required for the tool. The Linear Hexahedral type mesh elements were taken on the sheet for the analysis [10]. The same modelling conditions were applied for different temperatures by changing the temperature value in the predefined field. The results from the simulations were analysed and discussed in the upcoming section.

For validating the hypothesis that formability increases with increase in temperature, the experimental analysis was also performed. The same toolpath as used for simulation was converted to the machine compatible program. The dimension of tool and sheet blank were also kept the same, as taken in numerical analysis. The experiments were conducted by heating the sheet to different temperature ranges, varying from $100^{\circ} \mathrm{C}$ to $250^{\circ} \mathrm{C}$. For heating the sheet, an external heating source was placed just below the sheet as shown in Fig. 5. The temperature monitoring was done with the help of an infrared thermal camera. No lubricant was used during the experimentations. The formed truncated cone was then post-processed for analysing the influence of heat on the process. Besides, the outcomes were additionally compared with the results of the IF process without heat.

\section{Observations}

\subsection{Numerical simulation}

The results of the simulation were interpreted in terms of strain energy, stresses induced and final depth achieved in the components without any damage. The strain energy is the energy stored in the sheet during deformation. The more the strain energy, more forces are required to form the component. It was observed that as the temperature increases, the strain energy decreases. The decrement in strain energy was observed to be about $83 \%$ at $250^{\circ} \mathrm{C}$ in comparison to strain energy at $20^{\circ} \mathrm{C}$. Fig. 6 shows the plot of the strain energy versus time at different temperatures.

Stresses induced in the components are responsible for the deformation and, ultimately, for the failure of the component. While forming a component, it is always preferable that induced stresses are low. From the results of the simulation, it was observed that induced stresses are low for the IF processes carried out at higher temperatures. The stress induced in the components decreases by about $60 \%$ when the temperature increases from the room temperature to $250^{\circ} \mathrm{C}$. Fig. 7 shows the stresses induced in the parts.

The springback in the formed part is one of the major issues while forming the component at room temperature. Due to springbank, geometric changes occur in the part after the removal of forming forces. Springback is measured by finding the difference between the final depth formed to the desired depth of the component. It was observed that the springback reduces with the increase in temperature. Minimum springback of $0.37 \mathrm{~mm}$ was observed, while the temperature of forming was $250^{\circ} \mathrm{C}$. Fig. 8 shows the final depth achieved after IF process at different temperatures.

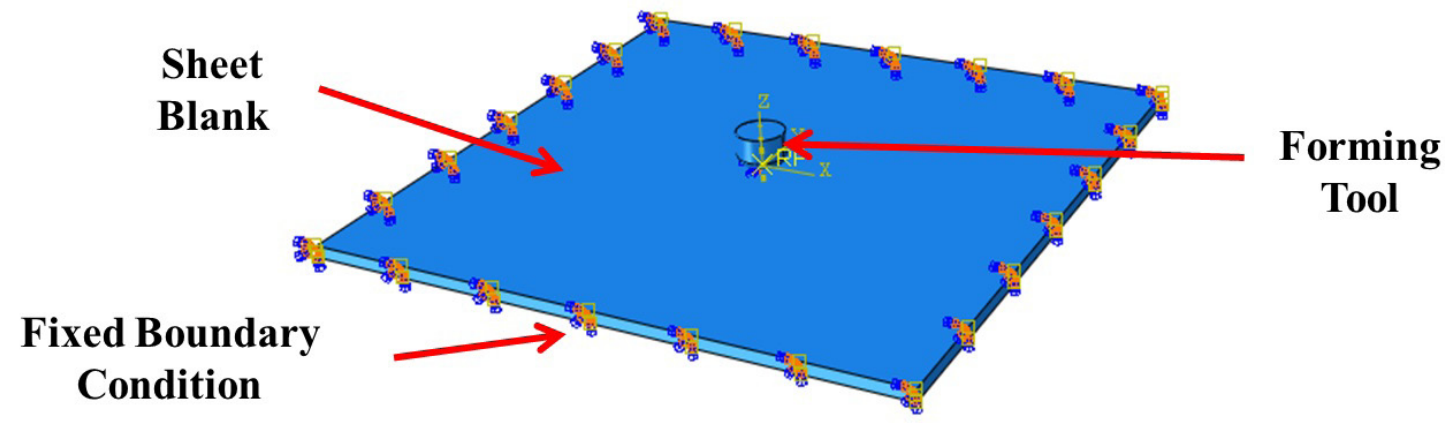

Fig. 4. (Color online) Assembled model for FEA.

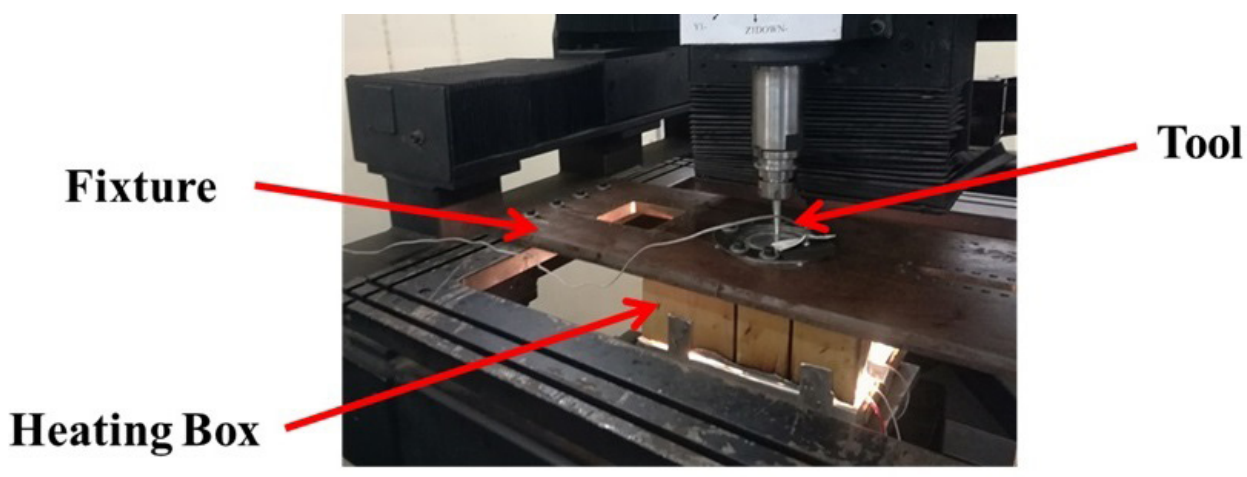

Fig. 5. (Color online) Setup for IF process with heat. 


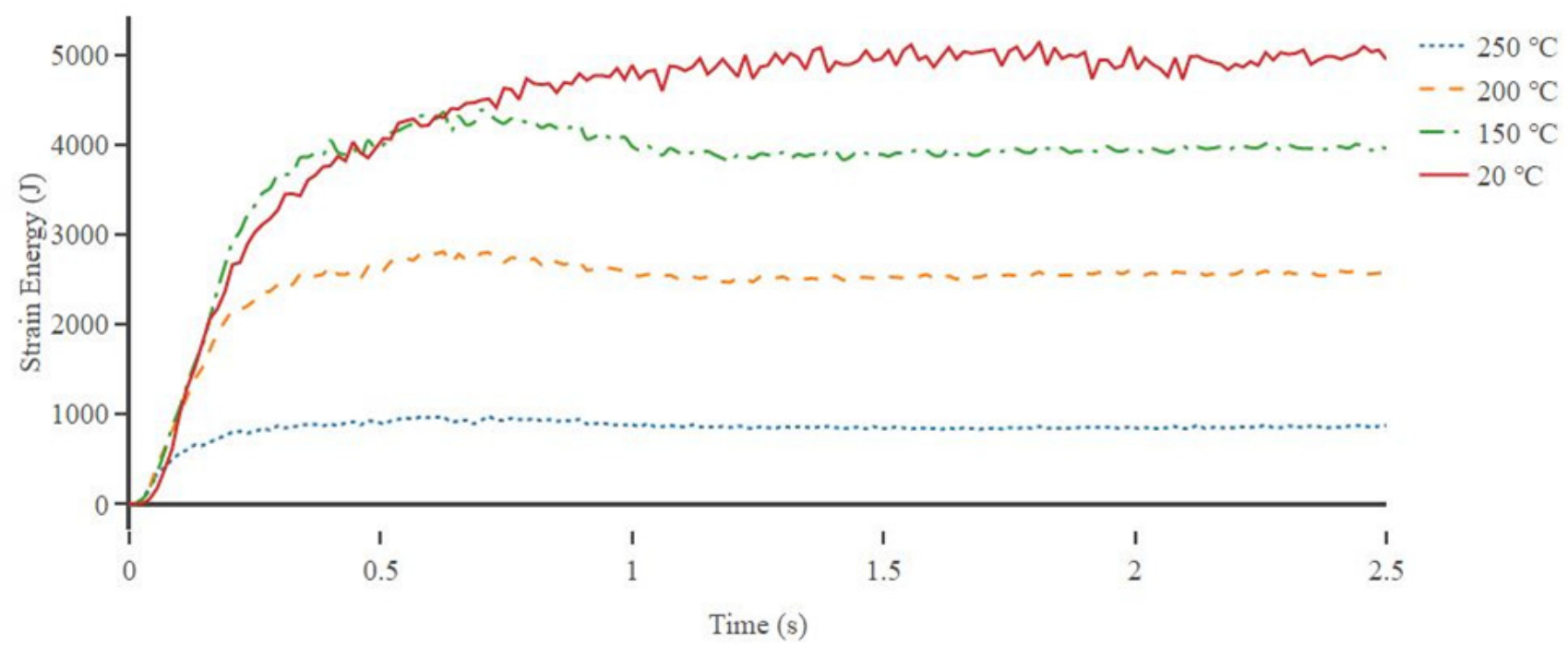

Fig. 6. (Color online) Strain energy versus time plot at different temperatures.

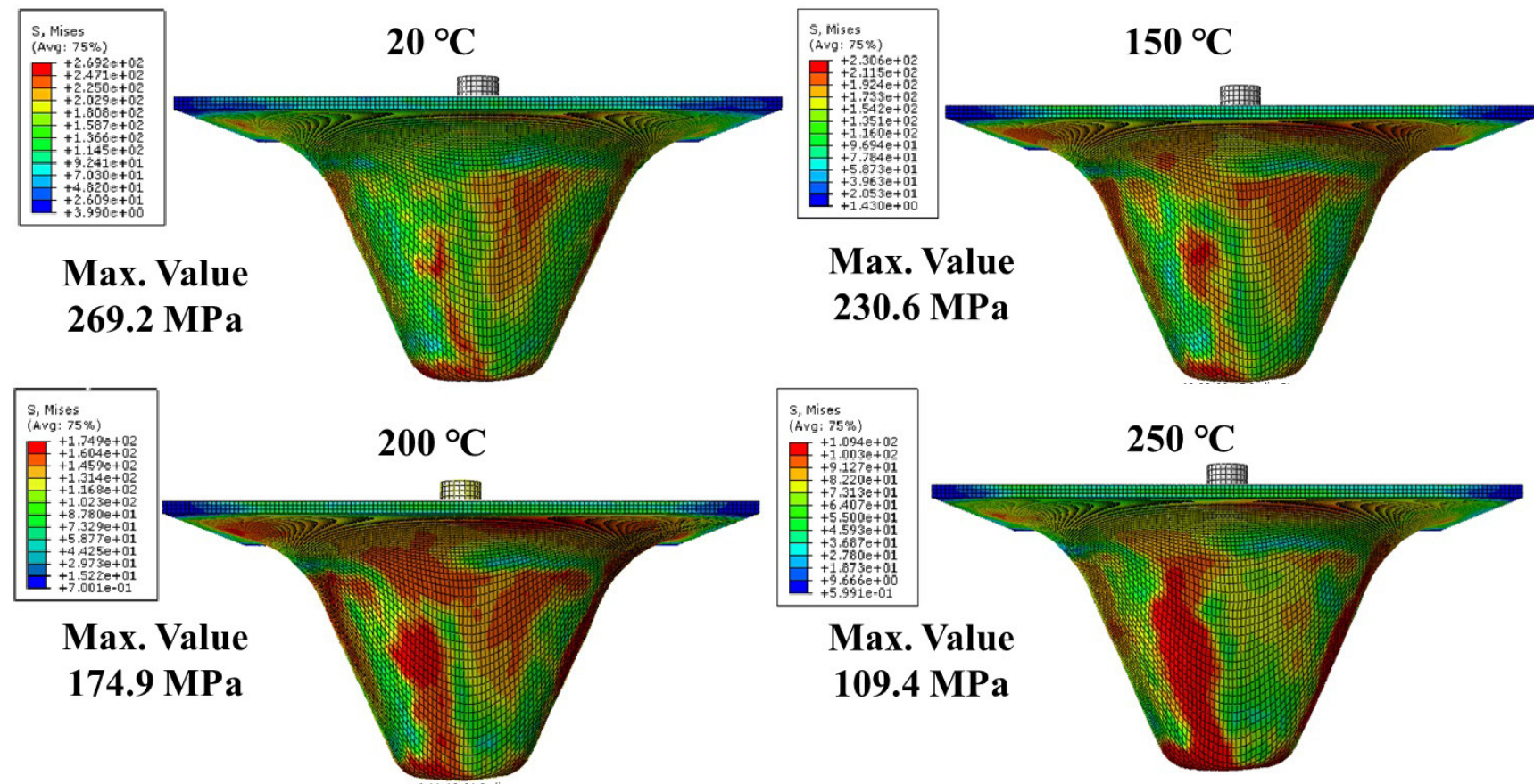

Fig. 7. (Color online) Stresses induced in components at different temperatures.

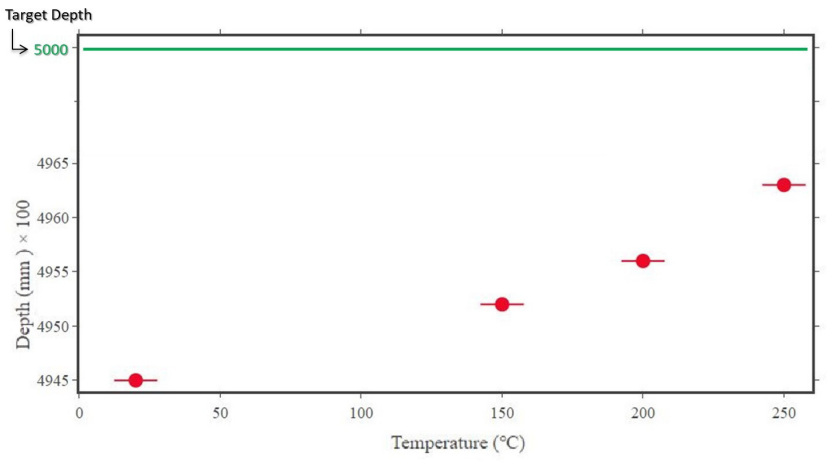

Fig. 8. Final depths achieved by IF at different temperatures.

\subsection{Experimental investigation}

Although numerous studies say that a higher temperature is favourable for the forming process, nothing is mentioned about the surface and product quality. To inspect the surface quality, the product was processed for surface roughness test and optical microscopy. However, just after the formation of the final product, it was evident from the visual inspection that when the temperature of forming is increased beyond $150^{\circ} \mathrm{C}$, the surface exposed to heat gets alligator skin, as shown in the Fig. 9. This was due to the uneven flow of material and coarse grain size formation on the surface [11].

The inner surface was inspected with Mitutoyo Surftest SJ500 and the surface roughness values obtained at different 


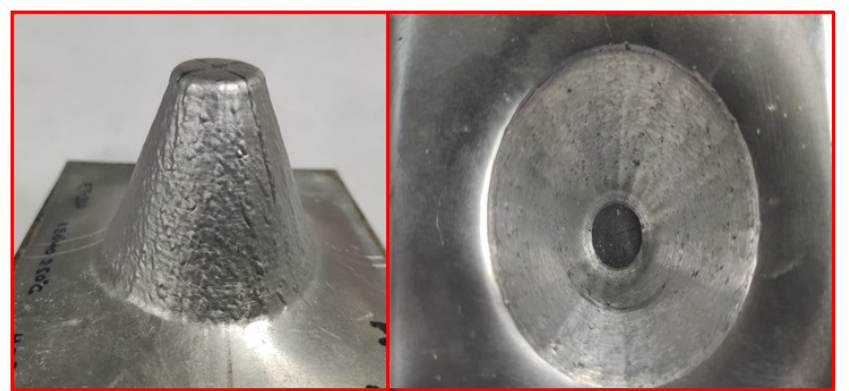

Below $200{ }^{\circ} \mathrm{C}$

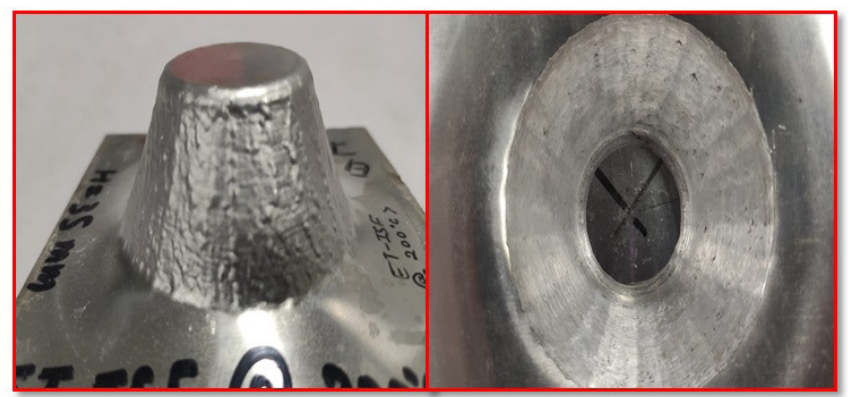

Above $200{ }^{\circ} \mathrm{C}$

Fig. 9. Appearance of components formed at temperature below and above $200^{\circ} \mathrm{C}$.

temperature ranges are collected in Table 1. The resulting trend follows a convex function. The surface quality initially improves with increase in temperature, but after $200^{\circ} \mathrm{C}$ temperature, it starts deteriorating. This is due to the formation of slag on the forming surface. Besides, the upper layer of the sheet starts sticking with the tip of the forming tool at higher temperatures, which makes the surface quality destitute.

For predicting the thickness of the formed component, the parts were scanned with ATOS optical 3D scanner. The minimum post forming sheet thickness values observed at different temperature ranges are illustrated in Table 2. The trend indicates that as the temperature increases, the minimum thickness of the sheet formed increases, but after $100^{\circ} \mathrm{C}$, the thickness starts decreasing again, and the formed component has the minimum sheet thickness at higher temperature.

Table 1. Roughness average $\left(R_{a}\right)$ values at different temperatures.

\begin{tabular}{|c|c|}
\hline Temperature $\left({ }^{\circ} \mathrm{C}\right)$ & Roughness average $\left(R_{a}\right)$ value $(\mu \mathrm{m})$ \\
\hline Room temperature & 2.52 \\
\hline 100 to 150 & 2.23 \\
\hline 150 to 200 & 2.32 \\
\hline Above 250 & 2.41 \\
\hline
\end{tabular}

Table 2. Minimum thickness values in different temperature ranges.

\begin{tabular}{|c|c|}
\hline Temperature $\left({ }^{\circ} \mathrm{C}\right)$ & Minimum thickness $(\mathrm{mm})$ \\
\hline Room temperature & 0.33 \\
\hline 100 to 150 & 0.37 \\
\hline Above 150 & 0.33 \\
\hline
\end{tabular}

\section{Conclusions}

The IF process offers solutions for manufacturing products with mass customization. However, it is not being adapted by the industries due to its inevitable limitations. This work was carried out to understand and reduce some of the process deficiencies. From the materials science, it is marked that heat plays a significant role in increasing the elongation property of the sheet. The research was conducted to determine the influence of heat on the IF process. From the literature data it follows that with preheating an AA1050 sheet up to $330^{\circ} \mathrm{C}$, the product quality improves. However, above this temperature, the quality starts degrading.

The numerical modelling was done to determine the temperature range at which IF produces the optimum results for AA1050. The simulation was done at different temperatures, and the results were analysed in terms of strain energy, stresses induced, and depth achieved. Based on the results, it was concluded that temperature close to $150^{\circ} \mathrm{C}$ produces excellent results. The experimental analysis was performed to watch the effect of heat on the IF process. The products made were inspected and the result from the inspections summarizes that high amount of heat degrades the product quality. Thus, it may be concluded that the temperature around $150^{\circ} \mathrm{C}$ offers the best solution to carry out IF process on $1 \mathrm{~mm}$ thick AA1050 sheet.

Acknowledgments. The authors wish to acknowledge Prof. Alexander Pesin (Nosov Magnitogorsk State Technical University, Russia) for his contribution in determining material properties by utilizing his lab facilities.

\section{References}

1. N. N. Powell, C. Andrew. Proceedings of the Institution of Mechanical Engineers, Part B: Journal of Engineering Manufacture. 206 (1), 41 (1992). Crossref

2. W.C. Emmens, G. Sebastiani, A. H. van den Boogaard. Journal of Materials Processing Technology. 210 (8), 981 (2010). Crossref

3. S. Matsubara. Proceedings of the Institution of Mechanical Engineers, Part B: Journal of Engineering Manufacture. 215 (7), 959 (2001). Crossref

4. D. M. Kang, K.I. Manabe. Transactions of Materials Processing. 14 (7), 607 (2005). $\underline{\text { Crossref }}$

5. P. Gupta, J. Jeswiet. The International Journal of Advanced Manufacturing Technology. 95, 3693 (2018). Crossref

6. J.R. Duflou, AM. Habraken, J. Cao, et al. International Journal of Material Forming. 11, 743 (2018). Crossref

7. P.J. Silva, A.J. Alvares. 2015 IEEE International Conference on Advanced Intelligent Mechatronics. (AIM). Busan, South Korea (2015) p. 808. Crossref

8. P. Shrivastava, P. Tandon. Transactions of the Indian Institute of Metals. 71, 2145 (2018). Crossref

9. P. Shrivastava, P. Tandon. Journal of Materials Processing Technology. 266, 292 (2019). Crossref

10. M. Sbayti, A. Ghiotti, R. Bahloul, H. Belhadjsalah, S. Bruschi. MATEC Web of Conferences. 80, 14006 (2016). Crossref

11. P. Shrivastava, P. Kumar, P. Tandon, et al. Journal of the Brazilian Society of Mechanical Sciences and Engineering. 40, 335 (2018). $\underline{\text { Crossref }}$ 